\title{
Effect of body mass and physical activity volume and intensity on pedometry-measured activity energy expendi- ture in rural black South Africans in the Limpopo Province
}

\author{
lan Cook (BA (Phys Ed) Hons, BSc (Med) Hons) ${ }^{1}$ \\ Marianne Alberts $(\mathrm{PhD})^{2}$ \\ Estelle V Lambert (PhD) ${ }^{3}$ \\ ${ }^{1}$ Physical Activity Epidemiology Laboratory, University of Limpopo (Turfloop Campus), Polokwane \\ 2 Department of Chemical Pathology, University of Limpopo (Turfloop Campus), Polokwane \\ ${ }^{3}$ MRC/UCT Research Unit for Exercise Science and Sports Medicine, Department of Human Biology, University of Cape Town
}

\begin{abstract}
Objectives. We developed a novel approach to investigate patterns of pedometry-measured total weekly activity energy expenditure $\left(E E_{A c t}\right)$ in rural black South Africans in the Limpopo Province.

Design. We analysed 7-day pedometry data in 775 subjects (female: $N=508$; male: $N=267$ ). Variance components models for $E_{\text {Act }}$ were used to estimate the variance explained by body mass (BM), total weekly steps (volume) and estimated intensity (kcal. $\mathrm{kg}^{-1} \cdot$ step $\left.^{-1}\right)$. Univariate General Linear Models, adjusting for age, $\mathrm{BM}$ and physical activity (PA) volume, were used to determine if $\mathrm{EE}_{\text {Act }}$ was primarily affected by volume or intensity.

Results. BM (13.1\%), PA intensity (24.4\%) and PA volume $(56.9 \%)$ explained $94.4 \%$ of the variance in $\mathrm{EE}_{\mathrm{Act}}$. Adjusted $\mathrm{EE}_{\mathrm{Act}}$

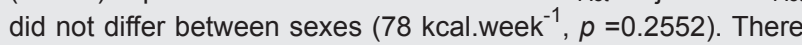
were no significant differences across activity categories (sedentary to very active) for adjusted $\mathrm{EE}_{\text {Act }}\left(62-287 \mathrm{kcal}\right.$ week $^{-1}$, $p>0.1)$. Adjusted $E_{\text {Act }}$ for $6-7$ days of compliance $(\geq 10000$ steps.day ${ }^{-1}$ ) differed significantly from $1-2$ days of compliance (266 - 419 kcal.week $^{-1}, p<0.04$ ). Obese (body mass index $\geq 30$ $\mathrm{kg} \cdot \mathrm{m}^{-2}$ ) and normal weight (body mass index $18.5-24.9 \mathrm{~kg} \cdot \mathrm{m}^{-2}$ ) women did not differ significantly across activity categories for $\mathrm{EE}_{\text {Act }}\left(200-592\right.$ kcal.week $\left.^{-1}, p>0.30\right)$.
\end{abstract}

\section{CORRESPONDENCE:}

Ian Cook

Physical Activity Epidemiology Laboratory

University of Limpopo (Turfloop Campus)

PO Box 459

Fauna Park

0787 Polokwane

South Africa

Tel+fax: +27 152682390

E-mail: ianc@ul.ac.za
Conclusions. We have highlighted an intensity effect for days of compliance and at very active ambulatory levels ( $\geq 12500$ steps. $\left.\mathrm{day}^{-1}\right)$. A volume effect appeared to dominate between sexes, across activity categories and weight-by-activity categories. It is important that post hoc statistical adjustments be made for body mass and $\mathrm{PA}$ volume when comparing $\mathrm{EE}_{\mathrm{Act}}$ across groups.

\section{Introduction}

Pedometry is considered a valid and reliable objective measure of free-living physical activity (PA). ${ }^{1}$ However, a disadvantage of this methodology is that the primary measure which is usually reported, namely the number of steps, provides no information as to the intensity of the ambulation. Consequently, it is not possible to disentangle the effects of volume and intensity of PA on outcome variables if statistical analyses only consider the number of steps (volume).

We recently reported high ambulation levels (average steps. $\operatorname{day}^{-1}$ ) for a rural African population in transition but could not provide definitive data pertaining to the intensity at which steps were accumulated. ${ }^{2}$ The study used a piezo-electric based pedometer (NL-2000) which stored both the number of steps and activity energy expenditure $\left(E E_{A c t}\right)^{2}$ The NL-2000 is produced by the Suzuken-Kenz Company (http://www.suzuken-kenz.com) for a North American distributor (New Lifestyles, http://www.new-lifestyles.com) and is identical in function to the Suzuken-Kenz e-STEP products (personal communication: Hitoshi Ozawa, Suzuken-Kenz, 17-052007). Therefore calibration results for the NL-2000 would also be applicable to the Suzuken-Kenz e-STEP products. ${ }^{3-5}$ Moreover, because the Suzuken-Kenz range includes the Lifecorder EX, which has been validated, ${ }^{6,7}$ and the technology in this high-end product is essentially the same as the lower-end products (except for the download capacity to a personal computer), the algorithms for all Suzuken-Kenz products would be identical. For instance, the NL2000 (e-STEP) (personal communication: Operations Manager, New Lifestyles, 02-09-2005) and the Lifecorder EX ${ }^{6}$ sense steps when there are three or more acceleration pulses for four consecutive seconds and calculate $\mathrm{EE}_{\mathrm{Act}}$ using body mass $(W)$ and an intensity dependent factor $(K a)$ such that $E E_{A c t}(\mathrm{kcal})=K a \times W(\mathrm{~kg})$. 


\begin{tabular}{|c|c|c|c|}
\hline & \multicolumn{2}{|c|}{ Residence } & \multirow[b]{2}{*}{$p^{\dagger}$} \\
\hline & Female $(N=508)$ & Male $(N=267)$ & \\
\hline \multicolumn{4}{|l|}{ Continuous variables } \\
\hline Age (years) & $40.1 \pm 20.7$ & $28.4 \pm 17.6$ & $<0.0001$ \\
\hline Body-mass-index $\left(\mathrm{kg} \cdot \mathrm{m}^{-2}\right)$ & $26.6 \pm 6.4$ & $21.2 \pm 3.9$ & $<0.0001$ \\
\hline Average steps.day ${ }^{-1}$ & $11086 \pm 4538$ & $14028 \pm 5434$ & $<0.0001$ \\
\hline Average activity EE (kcal.day ${ }^{-1}$ ) & $393 \pm 189$ & $491 \pm 213$ & $<0.0001$ \\
\hline Intensity factor (kcal. $\mathrm{kg}^{-1}$. step $\left.^{-1} \mathrm{x} 1000\right)$ & $0.58 \pm 0.28$ & $0.65 \pm 0.41$ & 0.0032 \\
\hline \multicolumn{4}{|l|}{ Categorical variables * } \\
\hline \multicolumn{4}{|l|}{ Body mass index classification } \\
\hline Normal weight $\left(<25 \mathrm{~kg} \cdot \mathrm{m}^{-2}\right)$ & $47.8(243)$ & $87.6(234)$ & $<0.0001$ \\
\hline Obese $\left(\geq 30 \mathrm{~kg} \cdot \mathrm{m}^{-2}\right)$ & $27.2(138)$ & $4.1(11)$ & $<0.0001$ \\
\hline \multicolumn{4}{|l|}{ Physical activity classification } \\
\hline Inactive $\left(<5000\right.$ steps.day $\left.^{-1}\right)$ & $10.2(52)$ & $3.0(8)$ & 0.0006 \\
\hline Active $\left(\geq 10000\right.$ steps.day $\left.^{-1}\right)$ & $59.4(302)$ & $77.9(208)$ & $<0.0001$ \\
\hline Completion of secondary school ( $\geq$ Grade 12 ) & $16.5(58)$ & $14.1(29)$ & 0.5420 \\
\hline Ownership of motor vehicle (Yes) & $21.2(99)$ & $18.1(45)$ & 0.3911 \\
\hline Electricity available inside house (Yes) & $75.4(353)$ & $65.3(162)$ & 0.0055 \\
\hline Water collected outside dwelling (Yes) & $8.5(40)$ & $8.1(20)$ & 0.9363 \\
\hline
\end{tabular}

Consequently, the $\mathrm{EE}_{\mathrm{Act}}$ displayed on the NL-2000 output is a function of the PA intensity (Ka), PA volume (number of steps) and the individual's body mass. It is thus not possible to ascertain if an $\mathrm{EE}_{\mathrm{Act}}$ difference between two individuals is due to increased PA (volume and/or intensity) or because of body mass differences. One approach to circumvent this problem is to use statistical methods to adjust for body mass and PA volume to ascertain whether $E_{\text {Act }}$ differences between two individuals are possibly intensity dependent. Therefore the objective of this study was to explore the patterns of pedometry-measured total weekly $\mathrm{EE}_{\mathrm{Act}}$ by statistically adjusting for body mass and PA volume to determine if PA intensity could be an important factor in explaining the high ambulatory levels in a rural African setting.

\section{Methods}

This analysis uses data for which the study protocol, subjects, field site, sample size and measurements have been described in detail elsewhere. $^{2}$ Briefly, 830 participants from the Dikgale Health and Demographic Surveillance System field site (DHDSS) ${ }^{8-11}$ were conveniently recruited and contacted twice over a 9-day period between January 2005 and December 2007. On the first occasion, subjects were recruited and completed the informed consent, relevant sections of a health questionnaire and provided anthropometric data. Standard anthropometric measurements and interviews were performed by trained, local fieldworkers and included measures of stature (nearest $1 \mathrm{~cm}$ ) and body mass (nearest $1 \mathrm{~kg}$ ). We categorised subjects using body mass index (BMI = body mass $\div$ stature $^{2}$, underweight: $<18.5 \mathrm{~kg} \cdot \mathrm{m}^{-2}$, normal weight: $18.5-24.9 \mathrm{~kg} \cdot \mathrm{m}^{-2}$, overweight: $25-29.9 \mathrm{~kg} \cdot \mathrm{m}^{-2}$, obese: $\left.\geq 30 \mathrm{~kg} \cdot \mathrm{m}^{-2}\right){ }^{12}$ Finally, subjects were instructed on the required procedures for wearing the pedometer over 9 consecutive days. We used piezo-electric pedometers (NL2000, New Lifestyles Inc., Kansas City, MO, USA) not affected by pedometer tilt or adiposity level ${ }^{13}$ to objectively measure PA. Data for day 1 and day 9 were omitted because these were incomplete days. The pedometer was worn on the right waist, securely attached to a nylon belt and sealed with surgical tape. The pedometers could be removed for sleeping and bathing purposes by unclipping the nyIon belt. Ambulation PA volume was defined as the average steps. day $^{-1}$ or steps.week ${ }^{-1}$. Energy expenditure was defined as total activity energy expenditure. week $^{-1}\left(E_{\text {Act }}\right.$, kcal.week $\left.{ }^{-1}\right)$. We calculated a PA intensity factor $\left(I_{F R}, k\right.$ cal. $\mathrm{kg}^{-1}$. step $\left.^{-1}\right)$ from the total weekly steps, total weekly $E_{\text {Act }}$ and body mass. Public health indices (thresholds) for steps.day ${ }^{-1}$ were defined as follows: ${ }^{14}$ sedentary: $<5000$ steps. day $^{-1}$, low active: $5000-7499$ steps.day $^{-1}$, somewhat active: 7500 - 9999 steps.day $^{-1}$, active: 10000 - 12499 steps.day $^{-1}$, and very active: $\geq 12500$ steps.day $^{-1}$. A summary variable was created indicating the number of days a subject was compliant or not for $0-7$ days $\left(\geq 10000\right.$ steps.day $\left.^{-1}\right)$. Subjects received a small honorarium on completion of the study. The study was approved by the Ethics Committee of the University of Limpopo (Turfloop Campus).

\section{Statistical analysis}

Descriptive statistics comprised means and 95\% confidence intervals $(95 \% \mathrm{Cl})$ or one standard deviation (SD). Independent $t$-tests were used to compare variables across gender. Variance components were estimated for inter-individual variance (body mass $=$ $\mathrm{kg}, \mathrm{PA}$ volume $=$ total weekly steps and $\left.\mathrm{I}_{\mathrm{FR}}=\mathrm{kcal}_{\mathrm{kg}} \mathrm{k}^{-1} \cdot \mathrm{step}^{-1}\right)$ and residual (intra-individual) variance. The variance components were also expressed as a percentage of the total variance. Inter-individual variance represents true variation between subjects while intraindividual variance represents unexplained variation within subjects. To identify additional variables that could affect the inter-individual variance we entered age and stature as covariates and sex, village and season as fixed factors. Multiple linear regression models, using backward selection, were used to examine the relative importance of PA volume, PA intensity and body mass to $E_{A c t}$. In addition to PA and body mass variables, age and sex were included in all initial models. Significance for variable entry into and exit out of the model were set at $p=0.05$ and $p=0.1$, respectively. Univariate General Linear Models (GLM) were used to compare ambulation (steps.day ${ }^{-1}$ ) and 


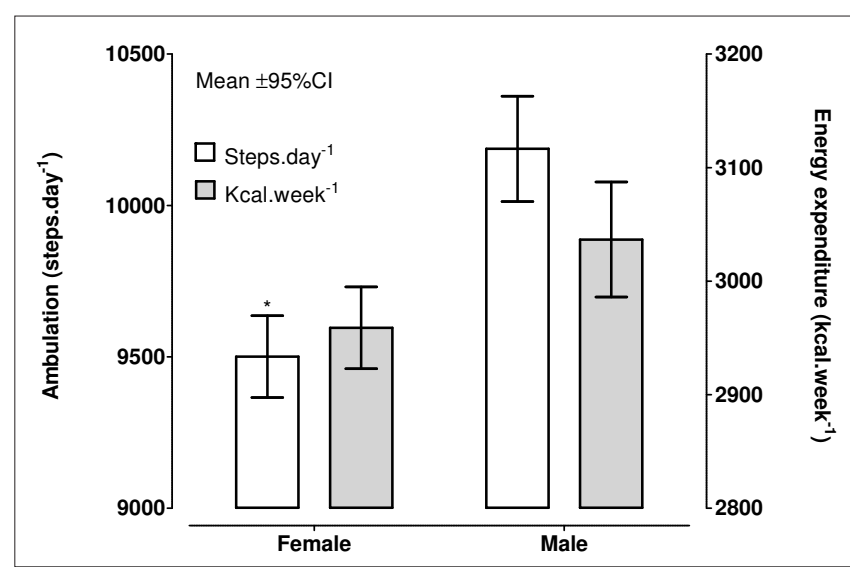

Fig. 1. Ambulatory and energy expenditure levels for males and females. Steps.day ${ }^{-1}$ adjusted for age and body mass. Kcal. week $k^{-1}$ adjusted for age, body mass and steps.week ${ }^{-1}$. "Steps. day $^{-1}$ : males $>$ females, $p<0.0001$.

$\mathrm{EE}_{\mathrm{Act}}\left(\mathrm{kcal}\right.$ week $^{-1}$ ) across gender, activity categories (sedentary to very active), days of non-compliance/compliance with public health guidelines $\left(\geq 10000\right.$ steps.day $\left.^{-1}\right)$, and obese- or normal-weight inactive (<7 500 steps.day $\left.^{-1}\right)$, active (10 $000-12499$ steps.day $\left.^{-1}\right)$ and very active $\left(\geq 12500\right.$ steps.day $\left.{ }^{-1}\right)$ participants. All initial models adjusted for age and body mass. Additional $\mathrm{EE}_{\mathrm{Act}}$ models were also constructed which adjusted for age, body mass and steps.week ${ }^{-1}$. Post hoc multiple comparison analyses (Sidak's $t$-test) assessed group differences. Data were analysed using appropriate statistical software (SPSS version 17.0.2). Significance for all inferential statistics was set at $p<0.05$.

\section{Results}

We excluded 14 outliers identified during exploratory data analysis. Because of very few obese males in the sample (Table I), only adult (19- 65 years) female subjects were used in the obese/normal weight comparison across activity categories.

The sizeable variance attributed to body mass $(13.1 \%)$, PA volume (total weekly steps, $56.9 \%)$ and IFR $\left(\mathrm{kcal}^{\mathrm{kgg}}{ }^{-1} \cdot \mathrm{step}^{-1}, 24.4 \%\right)$ suggested further analysis was warranted to determine if $E_{\text {Act }}$ group differences persist, possibly due to an intensity effect, by adjusting for body mass and PA volume. The $5.5 \%$ error variance was likely due to the rather crude $I_{F R}$ that was calculated. Entering age or stature as covariates, and sex, village or season as fixed factors, made no difference to variances $(<1 \%)$. Because the data were collected over 2 years in a number of villages that differ in terms of infrastructure and access to public transport, it was important to test whether season and village could explain part of the variance. $\mathrm{PA}$ volume, IFR and body mass were significant predictors of $\mathrm{EE}_{\mathrm{AC}}$ (model and coefficients: $p<0.0001$, model adjusted $\mathrm{R}^{2}=0.814$ ) and part correlations were $0.887,0.355$ and 0.259 , respectively. The multiple linear regression analysis revealed no collinearity between variables (variance inflation factors $<1.2$ ).

The adjusted $R^{2}$ for the partially (age and body mass) and fully (age, body mass and steps.wk ${ }^{-1}$ ) adjusted EE $E_{A c t}$ GLM models ranged from 0.130 to 0.564 and 0.690 to 0.695 , respectively $(p<0.0001)$. Males accumulated significantly more steps than females (687 steps.day $\left.{ }^{-1}, p<0.0001\right)$. (Fig. 1). The fully adjusted $\mathrm{EE}_{\text {Act }}$ was not significantly different (78 kcal.wk $\left.{ }^{-1}, p=0.2552\right)$ between sexes, suggesting no intensity effect (Fig. 1). However, adjusting for age and body mass only resulted in a significant difference $(224 \mathrm{kcal}$.

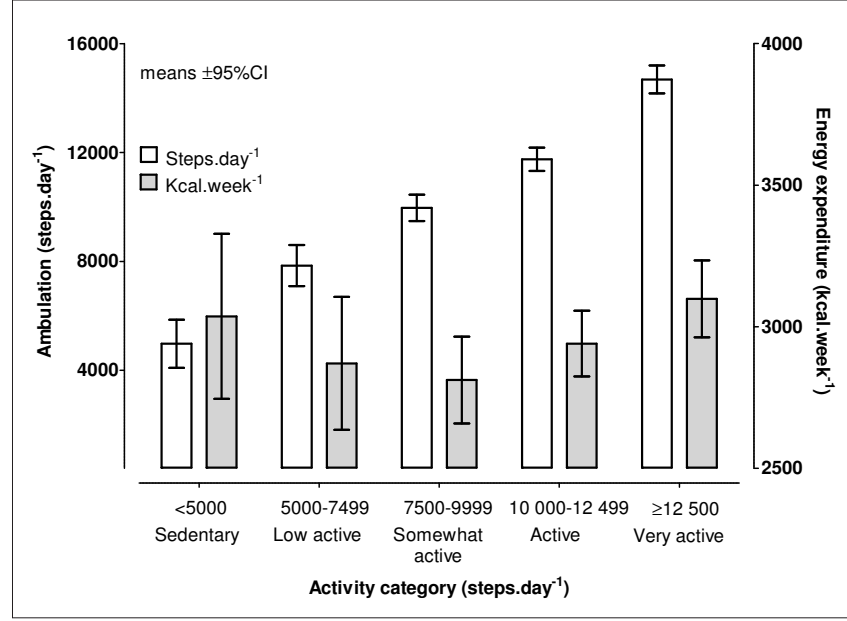

Fig. 2. Ambulatory and energy expenditure levels across activity categories. Steps.day ${ }^{-1}$ adjusted for age and body mass. Kcal. week $^{-1}$ adjusted for age, body mass and steps.wee $k^{-1}$. Steps. day $^{-1}$ : all activity categories significantly different, $p<0.0001$

week $^{-1}, p=0.0017$ ), suggesting that volume plays a more significant role in $\mathrm{EE}_{\text {Act }}$ differences between sexes.

Age and body mass-adjusted differences in steps across categories (sedentary - very active) were significant for all pairwise comparisons (1 783 steps.day ${ }^{-1}$ to 9710 steps.day $^{-1}, p<0.0001$ ) (Fig. 2 ). Adjusted for age and body mass, the middle three categories (low-active to active) resulted in relatively similar $\mathrm{EE}_{\mathrm{Act}},(p>0.1)$, but not so for two the extreme $E_{\text {Act }}$ categories (sedentary v. very active, $p<0.04$ ). However, the fully adjusted model yielded no significant differences across activity categories, suggesting a significant volume effect ( $p>0.1)$ (Fig. 2).

Age and body mass-adjusted steps.day ${ }^{-1}$ for $6-7$ days of compliance with public health guidelines $\left(\geq 10000\right.$ steps.day $\left.^{-1}\right)$ were significantly different to all other levels of compliance $(p<0.003)$ but there were no significant differences between 0 days (noncompliance) and 1 - 5 days of compliance ( $p>0.4)$ (Fig. 1). Adjusted for age and body mass, $E E_{\text {Act }}$ differed significantly for days of compliance $\geq 6$ compared with non-compliance ( 0 days) and lower levels of compliance $(1-5$ days) $(p<0.03)$. Significant differences persisted only for $E_{\text {Act }}$ for 6 - 7 days of compliance versus 1 - 2 days of compliance $(p<0.04)$, suggesting an intensity effect only for $6-7$ days of compliance (Fig. 3).

The $E_{\text {Act, }}$ adjusted for age and body mass of highly active normal weight and obese women was significantly higher than inactive normal weight and obese women (difference: 2224 2403 kcal.wk ${ }^{-1}, p<0.0001$ ). Adjusted for age, body mass and steps. week ${ }^{-1}$, obese and normal weight adult females did not differ in $\mathrm{EE}_{\text {Act }}$ for the three PA categories, suggesting that there are no statistical differences in PA intensity (Fig. 4). However, there was a tendency for normal weight females to have higher $E_{\text {Act }}\left(200 \mathrm{kcal}\right.$ week $^{-1}$ to $592 \mathrm{kcal}^{\text {.week }} \mathrm{k}^{-1}, p>0.30$ ).

\section{Discussion}

This is a novel study reporting for the first time volume and intensity effects from data obtained using pedometers. The analysis has highlighted an intensity effect for days of compliance and especially at very active ambulatory levels ( $\geq 12500$ steps.day $\left.{ }^{-1}\right)$. Interestingly, there did not seem to be a significant intensity effect between sexes, activity categories or obese versus normal weight across activity 


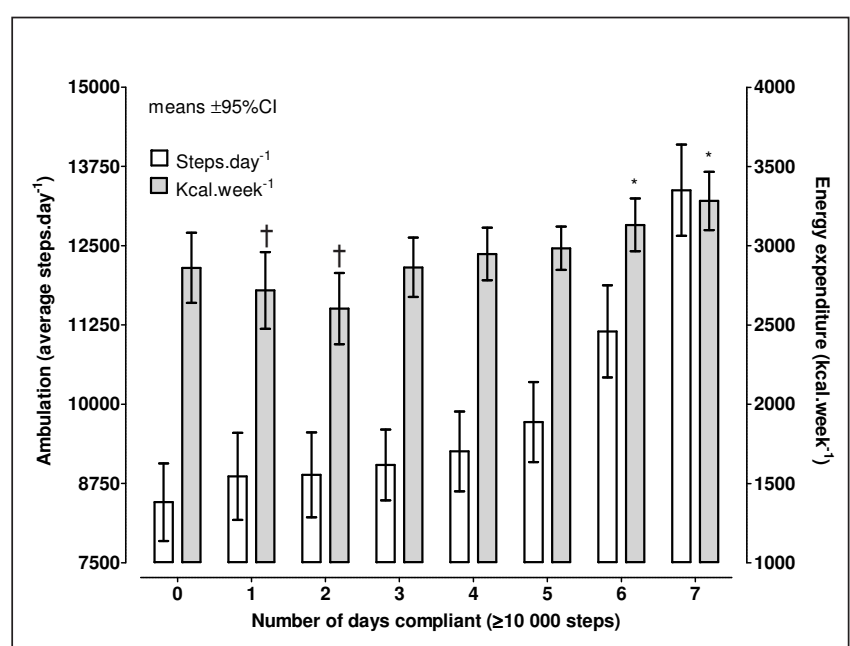

Fig. 3. Ambulatory and energy expenditure levels across number of days compliant $\left(\geq 10000\right.$ steps.day $\left.{ }^{-1}\right)$. Steps.day ${ }^{-1}$ adjusted for age and body mass. Kcal.week $k^{-1}$ adjusted for age, body mass and steps.week $k^{-1}$. Steps.day ${ }^{-1}: 6$ days and 7 days significantly different to all other days, $p<0.003 .{ }^{\dagger} K$ cal.week $k^{-1}$ : 1 - 2 days significantly different to 6 - 7 days, $p<0.04$.

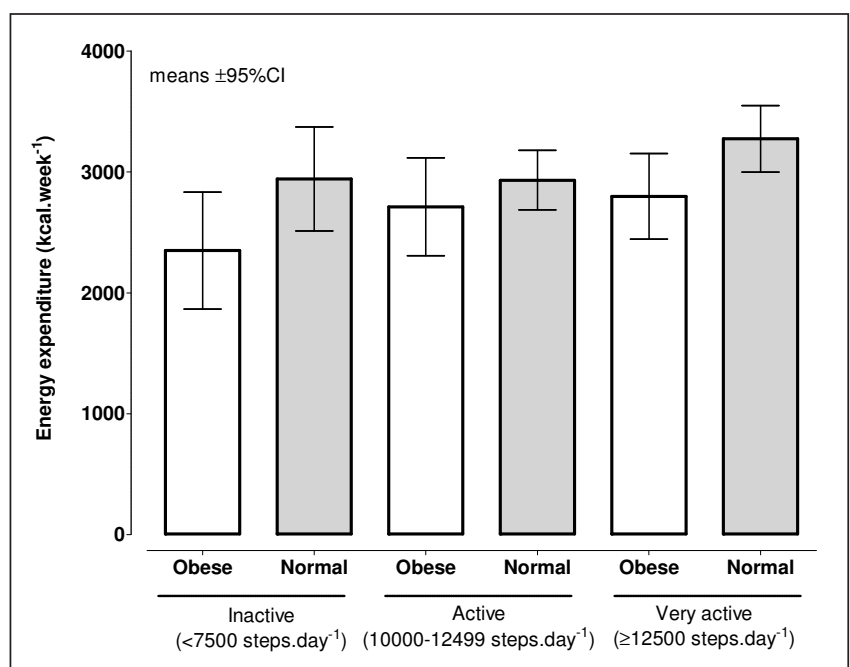

Fig. 4. Ambulatory and energy expenditure levels for normal weight and obese women across activity categories. Kcal. week $^{-1}$ adjusted for age, body mass and steps. week $k^{-1}$.

categories once age, body mass and accumulated steps had been adjusted for.

Differences in accumulated steps between males and females have been reported. ${ }^{15,16}$ Our results suggest that it is the difference in $\mathrm{PA}$ volume, and not PA intensity, that explains the difference in $\mathrm{EE}_{\mathrm{Act}}$ between males and females from this rural, African setting. Although average step totals increased significantly across activity categories, adjusted $E_{\text {Act }}$ did not increase accordingly. We also did not find markedly increased adjusted $E_{\text {Act }}$ between obese and normal weight females across activity categories, which is in agreement with findings of similar gross EE for walking and jogging at the same speed between normal weight and overweight/obese women, once adjusted for body mass and free fat mass. ${ }^{17}$ Furthermore, non-compliance or compliance on 1 - 5 days of the week with public health guidelines $\left(\geq 10000 \text { steps.day }{ }^{-1}\right)^{18}$ did not seem to reveal differences in $E_{\text {Act. }}$ However, complying on $6-7$ days, required significant increases in volume and intensity. These results suggest that public health PA guidelines of at least 5 times per week, 30 minutes per session, ${ }^{19}$ which equates to approximately 10000 steps.day ${ }^{-1},{ }^{20-22}$ were likely met through increases in accumulated steps throughout the day instead of increasing PA intensity. It was interesting that these findings would seem to provide non-intervention, free-living support for the feasibility of promoting moderate intensity PA such that the lack of a vigorous intensity requirement would not be a barrier to increasing PA. In other words, our results suggest that within this rural African population, walking behaviours are naturally modelled according to public health PA guidelines. However, highly active groups such as those achieving $\geq 12500$ steps on 6 or more days a week, required increases in intensity. This finding is in accord with the significantly higher accelerometer-measured moderate-tovigorous PA recorded for subjects achieving $\geq 11762$ steps. day $^{-1}$

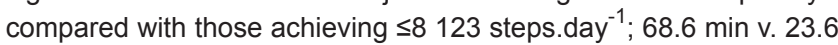
min, respectively $(p=0.000) .{ }^{22}$ Le Masurier et al. also reported higher moderate-to-vigorous activity for subjects achieving $\geq 10000$ steps. day $^{-1}$ compared with $<10000$ steps.day $^{-1}$ whether accumulated in bouts $\geq 1$-, $\geq 5$ - or $\geq 10$ min (difference: $p<0.05$ ). ${ }^{20}$ Recently, Dugas et al. suggested that PA intensity and not PA volume was a greater determinant of adiposity in young, black South African urban dwellers. ${ }^{23}$ Our results would suggest that the PA volume is the dominant contributor to $\mathrm{EE}_{\mathrm{Act}}$ in rural dwellers. Moreover, we have shown that average steps. day ${ }^{-1}$ is significantly associated with adiposity levels in rural African women $(r=-0.20, p=0.032){ }^{24}$

Several limitations must be acknowledged. Firstly, we could not compare our statistical adjustment against actual volume and intensity measures. Future analyses using uni-axial accelerometer data to ascertain at which intensity levels steps are being accumulated would provide more definitive answers as to the relative importance of PA volume and intensity, specifically within the context of a rural African setting. Secondly, the absolute $E_{\text {Act }}$ values reported in this study should be carefully interpreted because treadmill calibration studies for the NL-2000 suggest an overestimation of approximately $25 \%$ for $\mathrm{EE}_{\text {Act. }}{ }^{3}$

In conclusion, we have highlighted an intensity effect for $6-7$ days of compliance and at very active ambulatory levels. A volume effect appeared to dominate between sexes, across activity categories and weight-by-activity categories and would suggest that public health messages in this specific rural setting should focus on maintaining PA volume through daily living rather than advocating increases in PA intensity. It is important that post hoc statistical adjustments be made for body mass and PA volume when comparing $E_{\text {Act }}$ data across groups.

\section{Acknowledgements}

The Research Development and Administration Division of the University of Limpopo (Turfloop Campus) and the Thuthuka Programme of the National Research Foundation supported this study.

\section{REFERENCES}

1. Bassett DR, Strath SJ. Use of pedometers to assess physical activity. In Welk GJ ed. Physical activity assessments for health-related research. Champaign, IL: Human Kinetics 2002:163-177.

2. Cook I, Alberts M, Brits JS, Choma S, Mkhonto SS. Descriptive epidemiology of ambulatory activity in rural, black South Africans. Med Sci Sports Exerc 2010; (In press).

3. Crouter SE, Schneider PL, Karabulut M, Bassett DR. Validity of 10 electronic pedometers for measuring steps, distance, and energy cost. Med Sci Sports Exerc 2003;35:1455-1460. 
4. Schneider PL, Crouter SE, Lukajic O, Bassett DR. Accuracy and reliability of 10 pedometers for measuring steps over a $400-\mathrm{m}$ walk. Med Sci Sports Exerc 2003;35:1779-1784

5. Schneider PL, Crouter SE, Bassett DR. Pedometer measures of freeliving physical activity: comparison of 13 models. Med Sci Sports Exerc 2004;36:331-335

6. Kumahara $\mathrm{H}$, Schutz $\mathrm{Y}$, Ayabe $\mathrm{M}$, et al.The use of uniaxial accelerometry for the assessment of physical-activity-related energy expendimetry for the assessment of physical-activity-related energy expendi-
ture: a validation study against whole-body indirect calorimetry. Br J Nutr 2004;91:235-243.

7. McClain JJ, Craig CL, Sisson SB, Tudor-Locke C. Comparison of Lifecorder EX and ActiGraph accelerometers under free-living conditions. Appl Physiol Nutr Metab 2007;32:753-761.

8. Alberts M, Burger S. INDEPTH DSS Site Profiles: Dikgale DSS, South Africa. In: Sankoh OA, Kahn K, Mwageni E, Ngom P, Nyarko P, eds. Population and Health in Developing Countries.Volume 1. Population, Health and Survival at INDEPTH Sites. Ottawa: IDRC, 2002: 207-211.

9. Alberts M, Urdal P, Steyn K, et al. Prevalence of cardiovascular diseases and associated risk factors in a rural black population of South Africa. Eur J Cardiovasc Prev Rehabil 2005;12:347-354.

10. Cook I, Alberts M, Burger S, Byass P. All-cause mortality trends in Dikgale rural South Africa, 1996-2003. Scand J Public Health 2008;36:753-760.

11. Alberts M, Burger S, Tollman SM. The Dikgale field site. S Afr Med $J$ 1999;89:851-852.

12. Puoane T, Steyn K, Bradshaw D, et al. Obesity in South Africa: The South African Demographic and Health Survey. Obes Res 2002;10:1038-1048.

13. Crouter SE, Schneider PL, Bassett DR. Spring-levered versus piezoelectric pedometer accuracy in overweight and obese adults. Med Sci Sports Exerc 2005;37:1673-1679.
14. Tudor-Locke C, Bassett DR. How many steps/day are enough? Preliminary pedometer indices for public health. Sports Med 2004;34:1-8.

15. McCormack G, Giles-Corti B, Milligan R. Demographic and individual correlates of achieving 10,000 steps/day: use of pedometers in a populationbased study. Health Promot J Austr 2006;17:43-47.

16. Tudor-Locke C, Johnson WD, Katzmarzyk PT. Accelerometer-determined steps per day in US Adults. Med Sci Sports Exerc 2009;41:1384-1391.

17. Le Cheminant JD, Heden T, Smith J, Covington NK. Comparison of energy expenditure, economy, and pedometer counts between normal weight and overweight or obese women during a walking and jogging activity. Eur J Appl Physiol 2009;106:675-682.

18. Tudor-Locke C, Hatano Y, Pangrazi RP, Kang M. Revisiting "How Many Steps Are Enough?”. Med Sci Sports Exerc 2008;40:S537-S543.

19. Haskell WL, Lee IM, Pate RR, et al. Physical activity and public health: updated recommendation for adults from the American College of Sports Medicine and the American Heart Association. Med Sci Sports Exerc 2007:39:1423-1434.

20. Le Masurier GC, Sidman CL, Corbin CB. Accumulating 10,000 steps: does this meet current physical activity guidelines? Res Q Exerc Sport 2003;74:389-394.

21. Hultquist $\mathrm{CN}$, Albright $\mathrm{C}$, Thompson DL. Comparison of walking recommendations in previously inactive women. Med Sci Sports Exerc 2005;37: 676-683.

22. Macfarlane DJ, Chan D, Chan KL, Ho EY, Lee CC. Using three objective criteria to examine pedometer guidelines for free-living individuals. Eur $\mathrm{J}$ Appl Physiol 2008;104:435-444.

23. Dugas LR, Carstens MA, Ebersole $\mathrm{K}$, et al. Energy expenditure in young adult urban informal settlement dwellers in South Africa. Eur J Clin Nutr 2009;63:805-807. 